\title{
Adição de Lipídios na Ração de Vacas Leiteiras: Parâmetros Fermentativos Ruminais, Produção e Composição do Leite ${ }^{1}$
}

\section{Luiz Henrique Vargas ${ }^{2}$, Rogério de Paula Lana ${ }^{3}$, Gulab Newamdram Jham ${ }^{4}$, Ferlando Lima Santos ${ }^{2}$, Augusto César de Queiroz ${ }^{3}$, Antônio Bento Mancio ${ }^{3}$}

RESUMO - Objetivou-se avaliar o efeito de dois níveis de lipídios (3 e 7\%) na dieta de vacas em lactação e, dentro do nível de 7\% avaliar duas fontes de lipídios (grão de soja moído e óleo de soja), sobre a produção e composição do leite, os parâmetros ruminais, a atividade de produção de amônia pela microbiota ruminal e o consumo de MS. Foram usadas seis vacas multíparas holandesas, puras e mestiças, com $500 \mathrm{~kg}$ de peso corporal, 30 dias pós-parto e produção média de 20 litros de leite/dia, distribuídas em dois quadrados latinos 3x3. Cada período experimental teve duração de 23 dias, sendo 16 dias para adaptação à dieta e sete dias para coleta de amostras ruminais. A produção de leite foi medida diariamente duas vezes, do $15^{\circ}$ ao $23^{\circ}$ dia de cada período experimental, fazendo-se uma amostragem do leite para análises de proteína e gordura. As amostras de líquido ruminal foram coletadas manualmente, por intermédio de sonda esofágica, e filtradas em gaze. As produções de leite e leite corrigido para 4\%, proteína, gordura, lactose, sólidos totais, sólidos desengordurados e densidade não foram afetados pelo aumento de lipídios na dieta e nem pelas diferentes fontes de lipídios. Houve efeito depressivo de lipídios sobre a porcentagem de butirato e consumo de MS, sendo que o óleo de soja causou maior efeito. O pH aumentou somente com a inclusão de grão de soja moído na dieta. Os níveis de acetato, propionato, A:P, isobutirato, isovalerato, amônia e atividade de produção de amônia não sofreram efeito de tratamentos.

Palavras-chave: ácidos graxos voláteis, consumo, fermentação, $\mathrm{pH}$, rúmen

\section{Lipids in the Ration of Dairy Cows: Ruminal Fermentation Parameters, Milk Production and Composition}

\begin{abstract}
The objective of this research was to evaluate two levels of lipids ( 3 and 7\%) in the diet of milking cows, and to evaluate in the $7 \%$ lipids two lipid sources (crushed soybean and soybean oil), on milk production and composition, ruminal parameters, ammonia production by mixed ruminal bacteria and dry matter intake. Six mature Holstein cows, purebred or crossbred, $500 \mathrm{~kg}$ of live weight, 30 days after calving and milk production of 20 1/day, were assigned to a two $3 \times 3$ latin square. Each experimental period last 23 days, in which 16 was for adaptation and seven days for data and sampling collection. Milk production was measured twice daily, from the $15^{\text {th }}$ to the $23^{\text {rd }}$ day of each experimental period, and sampled for protein and fat analysis. Ruminal samples were collected by esophageal catheter and squeezed in cheesecloth. Milk and 4\% corrected milk, protein, fat, lactose, total solids, non fatty solids and density were not affected by lipids level and source in the diet. There was a negative effect of lipids on butyrate and dry matter intake, in which soybean oil caused the major effect. The $\mathrm{pH}$ increased in the crushed soybean diet only. Acetate, propionate, acetate:propionate, isobutyrate, isovalerate, ammonia and specific activity of ammonia production were not affected by the diets.
\end{abstract}

Key Words: intake, rumen, $\mathrm{pH}$, volatile fatty acids

\section{Introdução}

Após o parto, vacas leiteiras de alta produção demandam grandes quantidades de nutrientes para a síntese do leite. Para que esses nutrientes sejam supridos, é necessário que ocorra elevado consumo de alimentos de boa qualidade e de alta densidade energética. Porém, neste momento de maior necessidade, a vaca apresenta menor consumo de matéria seca, o que faz com que sua necessidade seja maior que a ingestão de nutrientes, fazendo com que as mesmas permaneçam por longo tempo em balanço negativo de energia. Portanto, uma correta formulação de rações para animais nestas condições é fundamental para o suprimento das exigências energéticas.

Para aumentar a concentração energética da dieta, é necessário aumentar a proporção de alimentos concentrados. Contudo, o fornecimento máximo de concentrado deve ser limitado, respeitando a necessidade de um mínimo de fibra para o funcionamen-

\footnotetext{
${ }_{1}^{1}$ Parte da tese de mestrado do primeiro autor, apresentada à Universidade Federal de Viçosa - Viçosa-MG.

2 Mestre pela Universidade Federal de Viçosa, CEP 36571-000, Viçosa-MG.; Bolsista da CAPES.

${ }_{3}^{3}$ Professordo Departamento de Zootecnia da Universidade Federal de Viçosa, CEP 36571-000, Viçosa-MG. E.mail: rlana@mail.ufv.br.Bolsista do CNPq.

${ }^{4}$ Professor do Departamento de Química da Universidade Federal de Viçosa, CEP 36571-000, Viçosa-MG. E.mail: gulab@mail.ufv.br
} 
to ideal do ambiente ruminal e manutenção dos teores de gordura do leite. Lipídios (óleo ou gordura) têm sido utilizados para aumentar a densidade energética das dietas, uma vez que a gordura tem 2,25 vezes mais conteúdo energético que os carboidratos (Reddy et al., 1994; Simas, 1998).

Várias fontes de lipídios têm sido extensamente pesquisadas, como gordura animal e sementes oleaginosas, tais como algodão e soja. O grão de soja contém, aproximadamente, $19 \%$ de gordura e $39 \%$ de proteína bruta (Stern \& Illg, 1991). Como a soja possui $10 \%$ mais energia líquida por quilo de matéria seca que o farelo (NRC, 1989) e é cultivada em quase todas as regiões do território nacional, a substituição do farelo de soja pelo grão de soja pode ser vantajosa, desde que não haja diminuição na produção de leite e que o preço seja vantajoso.

O fornecimento do grão de soja cru pode elevar a produção total de leite e o teor de gordura. O grão é rico em lipídios que, adicionados à ração, provocam um aumento da energia líquida consumida, o que resulta em um aumento na produção de leite, uma vez que o incremento da energia consumida permite melhorar a eficiência de produção (DePeters \& Cant, 1992).

As recomendações da literatura sobre as quantidades de grão de soja cru, moído, na dieta para vacas lactantes são diversas, podendo variar de 1,8 a 2,5 kg/ dia (Palmquist \& Jenkins, 1980). No entanto, Deresz et al. (1996) afirmaram que até $5,1 \mathrm{~kg} / \mathrm{vaca} / \mathrm{dia}$, divididos em três fornecimentos, não afetaram a produção nem a composição do leite. Outra recomendação foi que o concentrado poderia conter de 20 a $50 \%$ de grão de soja cru (Campos et al., 1995).

Com objetivo de avaliar o consumo de nutrientes e o coeficiente de digestibilidade em vacas lactantes alimentadas com grão de soja moído, Pereira et al. (1997) trabalharam com dois tratamentos, 0 e $30 \%$ de grão de soja moído no concentrado, e silagem de milho oferecida à vontade. Os autores observaram redução no consumo para o tratamento com $30 \%$ de grão de soja moído no concentrado, e não houve diferença para digestibilidade aparente dos nutrientes. Verificaram também a redução de 24,8 para 19,6 litros na produção de leite corrigida para 3,5\% de gordura em vacas recebendo ração concentrada com $30 \%$ de grão de soja moído, embora a composição do leite não tenha sido afetada.

O uso de óleo em rações para ruminantes apresenta efeitos desejáveis, como inibição da produção de metano, redução da concentração de $\mathrm{NH}_{3}$ ruminal, aumento na eficiência da síntese microbiana e aumento de ácido linoléico conjugado (CLA) no leite, que tem sido considerado um importante agente anticarcinogênico (Lin et al., 1995). Por outro lado, o óleo apresenta efeitos indesejáveis, como a redução na digestibilidade da matéria seca (MS) e redução na relação acetato:propionato com conseqüente diminuição da gordura do leite.

Segundo Palmquist (1991), a produção de leite não foi afetada pela fonte de gordura, porém, essa foi mais baixa quando os animais consumiram rações com maior teor de gordura. Schauff et al. (1992), em experimento com grão de soja integral e sebo bovino (2,5 e 4,0\%), observaram que as digestibilidades de MS, MO, celulose, conteúdo celular e PB diminuíram, quando gordura foi adicionada à dieta. Entretanto, as digestibilidades de FDA, FDN e hemicelulose não foram afetadas. Em trabalhos citados por Schneider \& Flatt (1975), rações contendo gorduras livres (óleos e sebos) promoveram aumento da digestibilidade de vários nutrientes da dieta. No entanto, quando o teor de gordura na MS era superior a 7\%, o consumo e a digestibilidade, principalmente da fibra, diminuíram tanto que se tornavam inferiores aos da ração controle, que não continha óleo.

Estudos realizados por Rabello (1995), Mora (1995) e Silva (1997) relataram que a produção e a composição do leite corrigidas para $4 \%$ de gordura, os consumos de matéria seca total, matéria seca do concentrado, matéria orgânica (MO), carboidratos totais (CHOT), nutrientes digestíveis totais (NDT), proteína bruta (PB), fibra em detergente neutro (FDN), $\mathrm{pH}$, amônia e síntese microbiana não foram afetados pela inclusão de grãos de soja moídos na ração concentrada. Porém, o consumo de extrato etéreo (EE) aumentou linearmente com o aumento dos níveis de grão de soja e as taxas de passagem da digesta ruminal diferiram entre si.

Malafaia (1995), trabalhando com sebo bovino, verificou que os consumos médios diários de MS, MO, PB, CHOT, FDN, NDT, a produção de leite corrigida para $3,5 \%$ de gordura e os teores de proteína bruta e gordura do leite não foram influenciados pela inclusão de sebo no concentrado. O consumo de EE e a produção de leite não corrigida foram influenciados pela adição de sebo. Durante um período de duas a quatro horas após a alimentação, os tratamentos que continham sebo resultaram em menores concentrações de amônia ruminal e maiores valores de $\mathrm{pH}$ do líquido ruminal. 
Murphy \& Morgan (1983) utilizaram 20 vacas da raça holandesa, aos 32 dias pós-parto, para testar três concentrados: cevada mais farelo de soja (controle), cevada mais farelo de soja com sebo não protegido e cevada mais farelo de soja com sebo protegido com formaldeído. O concentrado com sebo não protegido não obteve efeito significativo sobre a produção de leite, concentração de gordura e lactose no leite, porém estas foram aumentadas com o sebo protegido, mas a concentração de proteína diminuiu.

Van Nevel \& Demeyer (1988) observaram aumento de eficiência da síntese microbiana e redução da concentração de $\mathrm{NH}_{3}$ ruminal em animais recebendo óleo na dieta. Isto ocorreu, provavelmente, devido ao efeito sobre a defaunação (redução na produção de protozoários) e/ou pela redução na população de bactérias desaminadoras. Estes resultados foram confirmados por Lana \& Russell (1996), ao verificar que o óleo de milho, similarmente aos ionóforos monensina e lasalocida, aumentaram a resistência das bactérias ruminais à perda do potássio intracelular, quando as bactérias ruminais foram submetidas a níveis crescentes de ionóforos in vitro.

O objetivo do trabalho foi verificaros efeitos de níveis e fontes de óleo vegetal na ração de vacas leiteiras em início de lactação sobre os parâmetros de fermentação ruminal, tais como ácidos graxos voláteis (AGV), $\mathrm{pH}$ ruminal e amônia $\left(\mathrm{NH}_{3}\right)$, atividade de produção de amônia pela população microbiana ruminal(AEPA), consumo de MS e produção e composição do leite.

\section{Material e Métodos}

O experimento foi realizado no setor de bovinos do Departamento de Zootecnia (DZO) e as análises laboratoriais foram realizadas nos laboratórios de Nutrição Animal do DZO, Microbiologia de Anaeróbios do Departamento de Microbiologia, e Pesquisas em Produtos Naturais do Departamento de Química, todos da Universidade Federal de Viçosa, em Viçosa, MG.

Foram utilizadas seis vacas multíparas, holandesas e mestiças holandês-zebu, aproximadamente 30 dias após o parto, com peso médio de $500 \mathrm{~kg}$ e produção média de 20 litros de leite/dia. As vacas foram mantidas durante o dia em baias individuais cobertas, com piso de concreto, comedouros e bebedouros, e mantidas das 22 às 6 horas em um curral, nas dependências do estábulo, com acesso à água. A higienização das baias, comedouros e bebedouros foi feita diariamente. Os animais foram alimentados às $7 \mathrm{e}$ às 15 horas, recebendo o concentrado e o volumoso em dieta completa e ordenhados duas vezes/dia.

Os animais foram distribuídos em dois quadrados latinos $3 \times 3$ para o recebimento das diferentes dietas. Foram usadas três rações isoproteícas e isoenergéticas, diferindo-se pela fonte e teor de lipídios. O tratamento 1 (controle) continha 3\% de extrato etéreo, sendo que as rações dos demais tratamentos foram balanceadas para atingir um teor de $7 \%$ de extrato etéreo, usando soja integral moída (tratamento 2) e óleo de soja degomado (tratamento 3). As rações foram balanceadas para atender as exigências nutricionais das vacas de acordo com o NRC (1989). A composição das rações encontra-se na Tabela 1.

O experimento foi dividido em três períodos com duração de 23 dias, sendo 16 dias de adaptação à dieta e sete dias de coletas de dados. Diariamente, nos períodos de adaptação e de coletas, foram feitas pesagens e amostragens da silagem, do concentrado oferecido e das sobras. Após a amostragem, o material foi colocado em sacos plásticos, devidamente identificados e congelados a $-15^{\circ} \mathrm{C}$, e ao final de cada fase, foram descongelados e homogeneizados para se retirar uma amostra composta por animal/período, para posterior análises laboratoriais (Silva, 1990).

A produção de leite foi medida diariamente em

Tabela 1 - Composição da ração total

Table 1 - Composition of the total diet

\begin{tabular}{|c|c|c|c|}
\hline $\begin{array}{l}\text { Ingredientes (\%) } \\
\text { Ingredients }(\%)\end{array}$ & $\begin{array}{l}\text { Trat. } 1 \\
\text { Treat. } 1\end{array}$ & $\begin{array}{l}\text { Trat. } 2 \\
\text { Treat. } 2\end{array}$ & $\begin{array}{l}\text { Trat. } 3 \\
\text { Treat. } 3\end{array}$ \\
\hline $\begin{array}{l}\text { Silagem de sorgo } \\
\text { Sorghum silage }\end{array}$ & 59,5 & 70,0 & 74,4 \\
\hline $\begin{array}{l}\text { Milho } \\
\text { Corn grain }\end{array}$ & 22,2 & 5,5 & - \\
\hline $\begin{array}{l}\text { Farelo de soja } \\
\text { Soybean meal }\end{array}$ & 17,2 & - & 20,0 \\
\hline $\begin{array}{l}\text { Soja em grão } \\
\text { Whole soybean }\end{array}$ & - & 23,5 & - \\
\hline $\begin{array}{l}\text { Óleo de soja } \\
\text { Soybean oil }\end{array}$ & - & - & 4,6 \\
\hline $\begin{array}{l}\text { Mistura mineral } \\
\text { Mineral mixture }\end{array}$ & 1,1 & 1,0 & 1,0 \\
\hline $\begin{array}{l}\text { NDT } \\
T D N\end{array}$ & 70,0 & 70,0 & 70,0 \\
\hline $\begin{array}{l}\mathrm{PB} \\
C P\end{array}$ & 15,0 & 15,0 & 15,0 \\
\hline $\begin{array}{l}\mathrm{EE} \\
E E\end{array}$ & 3,0 & 7,0 & 7,0 \\
\hline
\end{tabular}


duas vezes, durante os períodos de coleta, e foi feita uma amostragem do leite para análises de proteína e gordura. Foram consideradas, para efeito de avaliação dos dados, apenas as produções de leite do $15^{\circ}$ ao $23^{\circ}$ dia de cada período experimental. Para corrigir o leite para $4 \%$ de gordura, utilizou-se a fórmula do NRC (1989):

$$
\mathrm{PLC}_{4 \%}=\mathrm{PL} \times\left[0,4+\left(\% \mathrm{G}_{\text {leite }} \times 0,15\right)\right]
$$

As análises de proteínas, gordura, lactose e sólidos totais foram determinadas por espectrometria de infravermelho em um aparelho B 2300 Combi (Bentley). A densidade das amostras foi determinada pela leitura direta em um termolactodensímetro, corrigindo-se o efeito da temperatura. $\mathrm{O}$ teor de sólidos desengordurados foi obtido pela subtração do percentual de gordura do percentual de sólidos totais. As duas últimas análises seguiram a metodologia descrita por Brasil (1981).

Para determinação da concentração de amônia, $\mathrm{pH}$ e $\mathrm{AGV}$ do líquido ruminal, as amostras foram coletadas manualmente, através de sonda esofágica e filtradas em gaze. Os tempos de coleta foram $0 ; 3$ e 6 horas após a alimentação da manhã. Foi feita leitura imediata do $\mathrm{pH}$ do líquido ruminal, utilizandose um potenciômetro. As amostras do líquido ruminal foram colocadas em dois tubos eppendorfs de $1,5 \mathrm{~mL}$, centrifugadas à $5200 \mathrm{x}$ g por 10 minutos, retirando-se os sobrenadantes com uma seringa até completar um terceiro tubo eppendorf para posterior congelamento. Foram feitas análises de amônia pelo método colorimétrico de Chaney \& Marbach (1962) e análises de AGV através da modificação do método descrito por Erwin et al. (1961).

Foram colocados $500 \mathrm{~mL}$ de amostra do líquido ruminal e $500 \mathrm{~mL}$ de ácido fosfórico (25\%) em tubos eppendorf de $1,5 \mathrm{~mL}$, homogeneizados, e após 20 minutos, centrifugados a $13000 \mathrm{x}$ g por 20 minutos. As análises dos líquidos sobrenadantes foram realizadas em um cromatógrafo a gás, modelo Shimadzu GC17 A com autoinjetor Shimadzu AOC17, através de um módulo de comunicação Shimadzu CBM-101, acoplado a um micro computador Pentium 100 com o software Class - GC10 versão 1.61. Os AGV foram separados em uma coluna $\mathrm{Nukol}^{\mathrm{TM}}$ capilar de sílica fundida (30 $\mathrm{m} \times 0,25 \mathrm{~mm} \times 0,25 \mathrm{~mm}$ Film Thickness, Supelco, Inc., Bellefonte, PA).

As condições utilizadas para a separação cromatográfica foram: temperatura da coluna $=100^{\circ} \mathrm{C}$ por 5 minutos, $185^{\circ} \mathrm{C}$ por 0 minuto; temperatura do injetor $=220^{\circ} \mathrm{C}$; temperatura do detector $=250^{\circ} \mathrm{C}$; tempo total $=13,5$ minutos; modo de controle $=$ split; pressão na coluna $(\mathrm{Kpa})=150$; fluxo na coluna $(\mathrm{mL} / \mathrm{min})$
$=1,90647$; velocidade linear $(\mathrm{cm} / \mathrm{s})=43,228$; fluxo total $=113$; taxa de split $=1: 40$. Os padrões de AGV foram do kit de ácidos orgânicos Supelco.

Para a análise da atividade específica de produção de amônia por bactérias ruminais, amostras separadas de líquido ruminal foram coletadas como descrito anteriormente. Estas amostras foram transportadas para o laboratório a $39^{\circ} \mathrm{C}$ e centrifugadas anaerobicamente a $500 \mathrm{xg}\left(5 \mathrm{~min}, 5^{\circ} \mathrm{C}\right)$ para eliminar as partículas alimentares e protozoários. A concentração de proteína bacteriana foi determinada através do método colorimétrico descrito por Lowry et al. (1951). Para isto, centrifugou-se $1,5 \mathrm{~mL}$ do líquido sobrenadante a $13000 \mathrm{x}$ g, por 5 minutos, seguindo-se de sucessivas ressuspensões e centrifugações do "pellet" bacteriano em solução de $\mathrm{NaCl}$ a $0,9 \%$ (p/v). Em seguida, foi feito o reestabelecimento do volume final com a solução fisiológica para 1,5 $\mathrm{mL}$ e armazenamento em tubos eppendorf a $-15^{\circ} \mathrm{C}$ para posterior análise.

Foram transferidos $9 \mathrm{~mL}$ do líquido sobrenadante da centrifugação a $500 \times$ g para tubos Vacuntainer ${ }^{\circledR}$, em triplicata, que foram então preenchidos com $\mathrm{CO}_{2}$ e vedados com rolha de borracha. No tempo zero, $1 \mathrm{~mL}$ de uma solução anaeróbica de Trypticase (BBL Microbiology Systems, Cockeysville, MD) foi adicionada aos tubos ( $15 \mathrm{~g} / \mathrm{L}$ de concentração final), sendo os mesmos incubados a $39^{\circ} \mathrm{C}$ por 4 horas. Foram coletados $2 \mathrm{~mL}$ do meio imediatamente antes e após a incubação, fazendo-se a centrifugação a $13000 \mathrm{x}$ g por 5 minutos para remoção das bactérias. O líquido sobrenadante foi armazenado a $-15^{\circ} \mathrm{C}$ para mensuração de amônia pelo método colorimétrico de Chaney \& Marbach (1962).

A atividade específica de produção de amônia (AEPA) foi determinada conforme fórmula abaixo (Lana \& Russell, 1997):

$\mathrm{AEPA}=\left(\mathrm{NH}_{3} \times 1.000 .000\right) /($ proteína microbiana * tempo de incubação)

em que: $\mathrm{AEPA}=\mathrm{nmol} \mathrm{NH}_{3} / \mathrm{mg}$ proteína microbiana/ minuto; $\mathrm{NH}_{3}=$ concentração final (4 horas) - inicial de amônia ( 0 horas), em mM; Proteína microbiana = concentração inicial, em mg/L; Tempo de incubação $=$ em minutos.

Os dados do experimento foram analisados em dois quadrados latinos $3 \times 3$. Cada animal em cada período correspondeu a uma unidade experimental. O modelo estatístico incluiu efeitos de animal, período e tratamentos. Os efeitos de tratamentos foram comparados por contrastes ortogonais completos: 1 controle vs outros e 2- óleo de soja vs soja integral 
moída. As análises estatísticas foram feitas usando o procedimento GLM do Minitab (Ryan \& Joiner, 1994) a $5 \%$ de probabilidade, e quando houve efeito significativo dos tratamentos, as médias foram comparadas pelo teste de Tukey a 5\% de probabilidade (Steel \& Torrie, 1980). Foram também traçadas as correlações entre acetato, propionato, butirato, relação acetato:propionato (A:P), isobutirato, isovalerato, $\mathrm{pH}$ e amônia.

\section{Resultados e Discussão}

As produções de leite e leite corrigido para 4\% de gordura não foram afetadas $(\mathrm{P}>0,05)$ pela inclusão de lipídios na dieta dos animais, com valores médios de 20,0 e $18,9 \mathrm{~kg} / \mathrm{dia}$, respectivamente. Tais resultados foram similares aos encontrados por Larson \& Schultz(1970), Grant \& Weidner(1992), Rabello(1995), McGuire et al. (1996) e Pinto (1997), pelo uso de lipídios não-protegidos nas dietas de vacas leiteiras.

Segundo Palmquist (1991), a produção de leite com e sem correção para $4 \%$ não sofreu efeito da inclusão de gordura na ração, principalmente quando esta não estava na forma protegida. Entretanto, Pinto (1997) obteve melhora na produção de leite em dieta contendo gordura protegida (Magnapac) comparado ao óleo de soja, ambos a 7\% de lipídios, e em relação ao controle, com $4 \%$ de lipídios.

Os tratamentos não afetaram a composição do leite, apresentando teores médios de 3,02\% de proteína e 3,64\% de gordura. Tais efeitos foram semelhantes aos obtidos por Palmquist (1991); Wu et al. (1994); Malafaia (1995); Rabello (1995); McGuire et al. (1996) e Silva (1997), porém contrários aos obtidos por Chow et al. (1990); Cant et al. (1991); Polan \& Fisher (1993) e Villela (1995), que obtiveram redução na proteína do leite.

O uso de lipídios também não afetou outros dados de composição do leite, como lactose, sólidos totais, sólidos desengordurados e densidade, apresentando dados médios de 4,45\%; $12,2 \% ; 8,56 \%$ e $1,03 \mathrm{~kg} / \mathrm{L}$, respectivamente. Outros autores (Wu et al., 1994; Silva, 1997; Pinto, 1997) obtiveram dados semelhantes quando suplementaram a ração de vacas lactantes com lipídios.

Lipídios insaturados inibiram as bactérias ruminais gram-positivas e estimularam aquelas produtoras de propionato, causando decréscimo na relação acetato:propionato e produção de metano (Richardson et al., 1976; Chalupa et al., 1984). O aumento da proporção molar de propionato foi devido ao aumento da produção com concomitante redução da produção de acetato e butirato (Van Nevel \& Demeyer, 1988).

A redução das perdas gasosas tem sido usada para explicar o efeito negativo sobre o consumo de matéria seca pelos inibidores microbianos, como os lipídios e ionóforos (Goodrich et al., 1984). Entretanto, neste experimento, houve efeito depressor dos lipídios sobre o consumo de matéria seca, sem contudo afetar os parâmetros ruminais, com excessão do butirato e $\mathrm{pH}$ (Tabela 2).

$\mathrm{O}$ efeito depressor dos lipídios sobre o consumo de matéria seca deve estar relacionado à inibição do crescimento microbiano e, conseqüentemente, fermentação da fibra, reduzindo, assim, a taxa de passagem da digesta pelo trato gastrintestinal. Esta inibição pode ser direta, conforme mencionado anteriormente, ou indireta, pela substituição do carboidrato por lipídio, mantendo-se as dietas isocalóricas. Neste caso, devido aos lipídios não serem fonte de energia para o crescimento microbiano.

Semelhante aos resultados desta pesquisa (Tabela 2), a maioria dos trabalhos pesquisados sobre o uso de lipídios saturados e insaturados tem demonstrado pequenos ou insignificante efeitos sobre os parâmetros ruminais. Larson \& Schultz (1970) não encontraram efeito na proporção dos ácidos acético, propiônico e butírico ao compararem dietas contendo ou não óleo de soja para vacas em lactação. Schauff et al. (1992), testando soja integral e/ou sebo bovino em dietas para vacas em lactação, observaram que a proporção molar de acetato e a relação acetato:propionato tenderam a decrescer nas dietas contendo lipídios. $\mathrm{OpH}$, as proporções molares de butirato, isovalerato e a concentração de amônia não foram alterados pelos tratamentos. Resultados similares foram encontrados por Stern et al. (1985), quando soja integral foi fornecida para vacas em lactação, e por Storry et al. (1973); Palmquist \& Conrad (1978, 1980); Palmquist et al. (1986, 1993) e Palmquist (1991), que usaram várias quantidades de sebo bovino na dieta.

Por outro lado, Balieiro Neto \& Melloti (1998), em dietas com $6 \%$ de sebo bovino, verificaram redução dos protozoários totais, redução na proporção molar dos ácidos acético e butírico e aumento do ácido propiônico com a adição de sebo, embora não tenha havido efeito sobre a ingestão de MS e concentração de N amoniacal. Shaw \& Ensor (1959) forneceram $150 \mathrm{~mL}$ de óleo de fígado de bacalhau duas vezes por dia para vacas leiteiras e encontraram um decréscimo da proporção de ácido acético, com um correspondente aumento em ácido propiônico. 
Tabela 2 - Efeito de fontes de lipídios para atingir $7 \%$ de extrato etéreo na ração de vacas leiteiras sobre o consumo de matéria seca (CMS); porcentagem de ácidos graxos voláteis, relação acetato:propionato, amônia e pH do líquido ruminal; e atividade específica de produção de amônia pela população microbiana ruminal in vitro (AEPA) ${ }^{1,2}$

Table 2 - Effect of lipid sources to reach 7\% ether extract in the ration of milking cows on dry matter intake (DMI); percentage of volatile fatty acids, acetate to propionate ratio, ammonia and ruminal $\mathrm{pH}$; and specific activity of ammonia production by mixed ruminal bacteria $(S A A P)^{1,2}$

\begin{tabular}{|c|c|c|c|c|}
\hline \multirow[b]{2}{*}{$\begin{array}{l}\text { Parâmetros } \\
\text { Parameters }\end{array}$} & \multicolumn{3}{|c|}{$\begin{array}{l}\text { Tratamento } \\
\text { Treatment }\end{array}$} & \multirow[b]{2}{*}{$\begin{array}{l}\text { Erro padrão } \\
\text { Standard error }\end{array}$} \\
\hline & $\begin{array}{c}\text { Controle } \\
\text { Control }\end{array}$ & $\begin{array}{l}\text { Grão } \\
\text { Grain }\end{array}$ & $\begin{array}{c}\text { Óleo } \\
\text { Oil }\end{array}$ & \\
\hline $\begin{array}{l}\mathrm{CMS}, \mathrm{kg} / \mathrm{d} \\
D M I\end{array}$ & $14,3^{\mathrm{a}}$ & $11,3^{b}$ & $11,0^{\mathrm{c}}$ & 0,69 \\
\hline $\begin{array}{l}\text { Acetato, \% } \\
\text { Acetate }\end{array}$ & 62,3 & 62,8 & 63,4 & 0,74 \\
\hline $\begin{array}{l}\text { Propionato, \% } \\
\text { Propionate }\end{array}$ & 20,2 & 20,8 & 21,7 & 0,46 \\
\hline $\begin{array}{l}\text { Butirato, \% } \\
\text { Butyrate }\end{array}$ & $9,65^{\mathrm{a}}$ & $7,99^{\mathrm{b}}$ & $7,70^{\mathrm{b}}$ & 0,33 \\
\hline $\begin{array}{l}\text { Isobutirato, \% } \\
\text { Isobutyrate }\end{array}$ & 3,11 & 3,77 & 3,26 & 0,16 \\
\hline $\begin{array}{l}\text { Isovalerato, \% } \\
\text { Isovalerate }\end{array}$ & 4,74 & 4,68 & 3,97 & 0,41 \\
\hline $\begin{array}{l}\mathrm{A}: \mathrm{P} \\
A: P\end{array}$ & 3,09 & 3,06 & 2,93 & 0,09 \\
\hline $\begin{array}{l}\text { Amônia, mM } \\
\text { Ammonia }\end{array}$ & 5,16 & 4,58 & 4,60 & 0,24 \\
\hline $\begin{array}{l}\mathrm{pH} \\
\mathrm{pH}\end{array}$ & $6,26^{\mathrm{b}}$ & $6,50^{\mathrm{a}}$ & $6,37^{\mathrm{b}}$ & 0,03 \\
\hline $\begin{array}{l}\text { AEPA } \\
\text { SAAP }\end{array}$ & 22,8 & 18,9 & 24,6 & 2,95 \\
\hline
\end{tabular}

${ }^{1}$ Médias seguidas por mesmas letras, na mesma linha, não diferem $(P>0,05)$ pelo teste de Tukey.

$2 \mathrm{nmol}$ de $\mathrm{NH}_{3} / \mathrm{mg}$ de proteína microbiana/minuto de incubação. Means followed by the same letters, in the same row, do not differ $(P>.05)$ by Tukey test.

$2 \mathrm{nmol}$ of $\mathrm{NH}_{3} / \mathrm{mg}$ of microbial protein/minute of incubation.

Christensen et al. (1994) não observaram efeito de dietas suplementadas com óleo de milho e sebo bovino sobre o pH ruminal, mas as concentrações de amônia foram reduzidas e as de isovalerato tenderam a reduzir. Neste experimento, houve aumento do $\mathrm{pH}$ pela fonte de lipídio, especialmente grão de soja, e tendência $(\mathrm{P}<0,10)$ à redução na produção de amônia e isovalerato. $\mathrm{O}$ aumento do $\mathrm{pH}$ foi provavelmente devido à queda no consumo de matéria seca e devido à menor fermentação ruminal, que proporciona menor acúmulo de ácidos graxos voláteis, principal fator de redução do $\mathrm{pH}$.

A concentração ruminal de amônia e dos ácidos graxos voláteis de cadeia ramificada, como o isovalerato, isobutirato e 2-metil butirato são indicativos da fermentação ruminal de aminoácidos. Observam-se na Tabela 3 boas correlações entre os níveis ruminais de isovalerato, isobutirato e amônia $(r>0,50)$, confirmando esta observação. A inibição no acúmulo de amônia e do isovalerato pelas fontes de lipídios (Tabela 2), embora não significativo, pode ser atribuída ao efeito depressor dos lipídios insaturados sobre a população de bactérias gram positivas, fermentadoras obrigatórias de aminoácidos para suprir suas necessidades energéticas e protéicas (Russell et al., 1988; Chen \& Russell, 1989). Ainda não foi demonstrado o efeito direto dos lipídios sobre essas bactérias, mas uma vez que os ácidos graxos insaturados apresentam propriedades similares aos ionóforos, tais como natureza apolar, inibição das bactérias ruminais ao nível de membrana e alteração dos parâmetros de fermentação (Chalupa et al., 1986), pode-se chegar a esta conclusão.

A atividade específica de produção de amônia pela população microbiana ruminal in vitro dá uma idéia sobre a população de microrganismos fermentadores de aminoácidos predominantes no rúmen em função da dieta. Três espécies de bactérias ruminais com alta capacidade de produção de amônia foram isoladas na década de 80 (Russell et al., 1988; Chen \& Russell, 1989), usando-se meios de cultura com alta concentração de peptídeos.

A população de bactérias especializadas em desaminar aminoácidos foi estimulada pelo aumento de proteína degradável na dieta e inibida pelos ionóforos (Yang \& Russell, 1993; Lana \& Russell, 1997) e pelo abaixamento do $\mathrm{pH}$ ruminal (Lana et al., 1998). Uma vez que os lipídios têm modo de ação sobre a população microbiana ruminal semelhante aos ionóforos (Lana \& Russell, 1996), era de se esperar redução na atividade de desaminação na presença dos lipídios. Entretanto, não foi verificado efeito dos lipídios sobre a desaminação (AEPA) (Tabela 2), assim como na maioria dos parâmetros de fermentação avaliados.

A relação acetato:propionato no líquido ruminal é influenciada pela dieta, variando de 3,5:1 em dieta à base de volumoso a 1,25:1 em dieta rica em concentrado (Nagaraja et al., 1997). Entretanto, Lana et al. (1998) verificaram maior correlação entre o pH que o nível de concentrado com a relação acetato:propionato. Foi verificada correlação positiva $(\mathrm{r}=0,50)$ entre o $\mathrm{pH}$ e a relação acetato:propionato neste experimento (Tabela 3), confirmando a importância da acidez no estímulo à produção de propionato no rúmen. 
Tabela 3 - Coeficientes de correlações lineares entre os parâmetros ruminais, em vacas lactantes recebendo grão de soja ou óleo de soja para atingir $7 \%$ de lipídios na ração total

Table 3 - Coefficients of linear correlation among ruminal parameters of milking cows receiving crushed soybean or soybean oil to reach $7 \%$ lipids in the total ration

\begin{tabular}{|c|c|c|c|c|c|c|c|}
\hline Item & $\begin{array}{l}\text { Acetato } \\
\text { Acetate }\end{array}$ & $\begin{array}{c}\text { Propionato } \\
\text { Propionate }\end{array}$ & $\begin{array}{l}\text { Butirato } \\
\text { Butyrate }\end{array}$ & $\begin{array}{l}\mathrm{A}: \mathrm{P} \\
A: P\end{array}$ & $\begin{array}{l}\text { Isobutirato } \\
\text { Isobutyrate }\end{array}$ & $\begin{array}{c}\text { Isovalerato } \\
\text { Isovalerate }\end{array}$ & $\mathrm{pH}$ \\
\hline $\begin{array}{l}\text { Propionato } \\
\text { Propionate }\end{array}$ & 0,928 & & & & & & \\
\hline $\begin{array}{l}\text { Butirato } \\
\text { Butyrate }\end{array}$ & 0,831 & 0,788 & & & & & \\
\hline $\begin{array}{l}\mathrm{A}: \mathrm{P} \\
A: P\end{array}$ & $-0,096$ & $-0,446$ & $-0,106$ & & & & \\
\hline $\begin{array}{l}\text { Isobutirato } \\
\text { Isobutvrate }\end{array}$ & 0,743 & 0,804 & 0,755 & $-0,397$ & & & \\
\hline $\begin{array}{l}\text { Isovalerato } \\
\text { Isovalerate }\end{array}$ & 0,649 & 0,712 & 0,778 & $-0,324$ & 0,746 & & \\
\hline $\begin{array}{l}\mathrm{pH} \\
\mathrm{pH}\end{array}$ & $-0,035$ & $-0,190$ & 0,075 & 0,503 & $-0,060$ & $-0,100$ & \\
\hline $\begin{array}{l}\text { Amônia } \\
\text { Ammonia }\end{array}$ & 0,377 & 0,303 & 0,696 & 0,071 & 0,499 & 0,609 & 0,149 \\
\hline
\end{tabular}

\section{Conclusões}

As fontes de lipídios reduziram em $20 \%$ o consumo de matéria seca, sem, contudo, afetar a produção e composição do leite e os parâmetros fermentativos ruminais, com exceção do butirato, que foi reduzido, e $\mathrm{pH}$, que aumentou na dieta contendo grão de soja.

\section{Literatura Citada}

BALIEIRO NETO, G.; MELLOTI, L. Efeitos de diferentes níveis de sebo sobre a fermentação ruminal, contagem de protozoários, proporção de ácidos graxos voláteis e degradabilidade in situ do farelo de soja e do feno de tifton (Cynodon dactylon). In: CONGRESSO NORDESTINO DE PRODUÇÃO ANIMAL, 1., 1998, Fortaleza, Ministério da Agricultura. Anais ... Fortaleza: 1998. p.9.

BRASIL. Ministério da Agricultura. Métodos analíticos oficiais para controle de produtos de origem animal e seus ingredientes. II. Métodos físicos e químicos. Brasília: Secretaria Nacional de Defesa Agropecuária. Laboratório Nacional de Defesa Animal, 1981.87p.

CAMPOS, O.F.; LIZIEIRE, R.S.; DAYRELL, M.S. et al. Características e composição de alguns alimentos concentrados utilizados na alimentação de bovinos de leite. Coronel Pacheco: Empresa Brasileira de Pesquisa Agropecuária/ CNPGL, 1995. (Circular Técnica, 38)

CANT, J.P.; DePETERS, E.J.; BALDWIN, R.L. Effect of dietary fat and postruminal casein administration on milk composition of lactating dairy cows. Journal of Dairy Science, v.74, p.211-219, 1991.

CHALUPA, W.; RICKABAUGH, B.; HRONFELS, D.S. et al. Rumen fermentation in vitro as influenced by long chain fatty acids. Journal of Dairy Science, v.67, p.1439-1444, 1984.

CHALUPA, W.; VECCHIARELLI, B.; ELSER, A.E. et al. Ruminal fermentation in vitro as influenced by long-chain fatty acids. Journal of Dairy Science, v.69, n.5, p.1293-1301, 1986.

CHANEY, A.L.; MARBACH, E.P. Modified reagents for determination of urea and ammonia. Clinical Chemistry, v.8, p.130-132, 1962.

CHEN, M.; RUSSELL, J.B. More monensin-sensitive, ammoniaproducing bacteria from the rumen. Applied and Environmental Microbiology, v.55, p.1052-1057, 1989.

CHOW, J.M.; DEPETERS, E.J.; BALDWIN, R.L. Effect of rumen-protected methionine and lysine on casein in milk when diets high in fat or concentrate are fed. Journal of Dairy Science, v.73, n.4, p.1051-1061, 1990.

CHRISTENSEN, R.A.; CAMERON, M.R.; CLARK, J.H. et al. Effects of amount of protein and ruminally protected amino acids in the diet of dairy cows fed supplemental fat. Journal of Dairy Science, v.77, n.6, p.1618-1629, 1994.

DePETERS, E.J.; CANT, J.T. Nutritional factors influencing the nitrogen composition of bovine milk. Journal of Dairy Science, v.75, n.8, p.2043-2070, 1992.

DERESZ, F.; FERNANDES, A.M.; MATOS, L.L et al. Utilização de soja grão crua na alimentação de vacas leiteiras de alta produção. Revista Brasileira de Zootecnia, v.25, n.1, p.113-124, 1996.

ERWIN, E.S.; MARCO, G.J.; EMERY, E.M. Volatile fatty acid analyses of blood and rumen fluid by gas chromatography. Journal of Dairy Science, v.44, n.9, p.1768-1771, 1961.

GOODRICH, R.D.; GARRET, J.E.; GAST, D.R. et al. Influence of monensin on the performance of cattle. Journal of Animal Science, v.58, p.1484-1498.

GRANT, R.J.; WEIDNER, S.J. Effect of fat from whole soybeans on performance of dairy cows fed rations differing in the fiber level particle size. Journal of Dairy Science, v.75, n.10, p.2742-2751, 1992.

LANA, R.P.; RUSSELL, J.B. Use of potassium depletion to asses adaptation of ruminal bacteria of ionophores. Applied and Environmental Microbiology, v.62, n. 12, p.4499-4503, 1996.

LANA,R.P.;RUSSELL, J.B.Effect of forage quality and monensin on the ruminal fermentation of fistulated cows fed continuously at a constant intake. Journal of Animal Science, v.75, p.224-229, 1997.

LANA, R.P.; RUSSELL, J.B.; Van AMBURGH, M.E. The role of $\mathrm{pH}$ in regulating ruminal methane e ammonia production. Journal of Animal Science, v.76, p.2190-2196, 1998.

LARSON, S.A.; SCHULTZ, L.H. Effects of soybeans compared to soybeans oil and meal in the ration of dairy cows. Journal

R. Bras. Zootec., v.31, n.1, p.522-529, 2002 (suplemento) 
of Dairy Science, v.53, p.9, p.1233-1240, 1970.

LIN, H.; BOYSLON, T.D.; CHANG, M.J. et al. Survey of the conjugated linoleic acid contents of dairy products. Journal of Dairy Science, v.78, n.11, p.2358-2365, 1995.

LOWRY, O.H.; ROSEBROUGH, N.J.; FARR, A.L. et al. Protein measurement with the Folin phenol reagent. Journal of Biology Chemistry, v.193, p.265-275, 1951.

MALAFAIA, P.A.M. Consumo e digestão dos nutrientes, eficiência microbiana, produção e composição do leite em vacas alimentadas com rações contendo sebo bovino. Viçosa, MG: Universidade Federal de Viçosa, 1995. 95p. Dissertação(Mestrado em Zootecnia) - Universidade Federal de Viçosa, 1995.

McGUIRE, M.A.; McGUIRE, M.K.; GUY, M.A. et al. Effect of dietary lipid concentration on content of conjugated linoleic acid (CLA) in milk from dairy cattle. Journal of Animal Science, v.74, S1, p.266, 1996.

MORA, P.J.G. Utilização de diferentes níveis de grão de soja (Glycine max L.) cru moído em rações concentradas e determinação da energia líquida da silagem de milho (Zea mays L.) para vacas em lactação. Viçosa, MG: Universidade Federal de Viçosa, 1995. 104p. Dissertação (Mestrado em Zootecnia) - Universidade Federal de Viçosa, 1995.

MURPHY, J.J.; MORGAN, D.J. Effect of inclusion of protected and unprotected in the supplement on the performance of lactating dairy cows. Animal Production, v.37, p.203-210, 1983.

NAGARAJA, T.G.; NEWBOLD, C.J.; Van NEVEL, C.J. et al. Manipulation of ruminal fermentation. In: HOBSON, P.N.; STEWART, C.S. (Eds.) The rumen microbial ecosystem 2.ed. London: Blackie Academic \& Professional, 1997. p.523-632.

NATIONAL RESEARCH COUNCIL - NRC. Nutrient requirements of dairy cattle. 6.ed. Washington, D.C.: National Academic Science, 1989. 158p.

PALMQUIST, D.L. Influence of source and amount of dietary fat on digestibility in lactating cows. Journal of Dairy Science, v.74, n.4, p.1354-1360, 1991.

PALMQUIST, D.L.; CONRAD, H.R. High fat rations for dairy cows. Effects on feed intake, milk and fat production, and plasma metabolites. Journal of Dairy Science, v.61, n.7, p.890-901, 1978.

PALMQUIST, D.L.; CONRAD, H.R. High fat rations for dairy cows. Tallow and hydrolyzed blended fat at two intakes. Journal of Dairy Science, v.63, n.3, p.391-395, 1980.

PALMQUIST, D.L.; JENKINS, T.C. Fat in lactation rations: review. Journal of Dairy Science, v.63, n.1, p.1-14, 1980.

PALMQUIST, D.L.; JENKINS, T.C.; JOYNER Jr., A.E. Effect of dietary fat and calcium source on insoluble soap formation in the rumen. Journal of Dairy Science, v.69, n.4, p.1020$1025,1986$.

PALMQUIST, D.L.; WEISBJERG, M.R.; HVELPLUND, T. Ruminal, intestinal, and total digestibilities of nutrients in cows fed diets high in fat and undegradable protein. Journal of Dairy Science, v.76, n.5, p.1353-1364, 1993.

PEREIRA, C.M.A. et al. Consumo e digestibilidade dos nutrientes para vacas em lactação alimentadas com grão de soja moído no concentrado. In: REUNIÃO ANUAL DA SOCIEDADE BRASILEIRA DE ZOOTECNIA, 34., 1997, Juiz de Fora. Anais ... Viçosa: Sociedade Brasileira de Zootecnia, 1997. p.262-264.

PINTO, S.M. Produção e composição química do leite de vacas holandesa no início da lactação alimentadas com diferentes fontes de lipídeos. Lavras: Universidade Federal de Lavras, 1997. 114p. Dissertação (Mestrado em Zootecnia) - Universidade Federal de Lavras, 1997.

POLAN, C.E.; FISHER, R.J. Nutrition can affect concentration of milk protein. Feedstuffs, v.65, n.4, p.15-21, 1993.

RABELLO, T.M. Grão de soja moído na alimentação de vacas lactantes. Viçosa, MG: Universidade Federal de Viçosa, 1995. 114p. Dissertação (Mestrado em Zootecnia) - Univer- sidade Federal de Viçosa, 1995.

REDDY, P.V.; MORRIL, J.L.; NAGARAJA, T.G. Release of fatty acids from raw or processed soybeans and subsequent effects on fiber digestibilities. Journal of Dairy Science, v.77, p.341-346, 1994.

RICHARDSON, L.F.; RAUN, A.P.; POTTER, E.L. et al. Effect of monensin on ruminal fermentation in vitro. Journal of Animal Science, v.43, p.657-664, 1976.

RUSSELL, J.B.; STROBEL, H.J.; CHEN, G. The enrichment and isolation of a ruminal bacterium with a very high specific activity of ammonia production. Applied and Environmental Microbiology, v.54, p.872-877, 1988.

RYAN, B.F.; JOINER, B.L. Minitab handbook. 3.ed. Belmont: Duxbury Press, 1994. 448p.

SCHAUFF, D.J. Effects of feeding lactating dairy cows diets containing soybeans and tallow. Journal of Dairy Science, v.75, p.1923-1935, 1992.

SCHNEIDER, B.H.; FLATT, W.P. The evaluation of feeds through digestibility experiments. Athens: University of Georgia Press, 1975. 423p.

SHAW, J.C.; ENSOR, W.L. Effect of feeding cod-liver oil and unsaturated fatty acids on rumen volatile fatty acids and milk fat content. Journal of Dairy Science, v.42, p.1238-1243, 1959.

SILVA, C.M.A.P. Produção e composição do leite, variação de peso corporal e digestibilidade em vacas alimentadas com ração contendo grão de soja moído no concentrado. Viçosa, MG: Universidade Federal de Viçosa. 1997. 72p. Dissertação (Mestrado em Zootecnia) - Universidade Federal de Viçosa, 1997.

SILVA, D.J. Análise de alimentos (métodos químicos e biológicos). Viçosa, MG: Universidade Federal de Viçosa, 1990. 165p.

SIMAS, J.M.C. Como utilizar gordura em dieta de vacas leiteiras. Revista Balde Branco, v.34, n.401, p.26-30, 1998.

STEEL, R.G.D.; TORRIE, J.H. Principles and procedures of statistics: a biometrical approach. 2.ed. New York: McGraw - Hill Publishing, 1980.

STERN, M.D.; ILLG, D.J. Empleo de soya integral e la alimentación de ruminantes. Soya Not., v.20, p.277-14-20, 1991.

STERN, M.D.; SANTOS, K.A.; SATTER, L.D. Protein degradation in rumen and amino acid absorption in small intestine of lactating dairy cattle fed heat-treated whole soybeans. Journal of Dairy Science, v.68, n.1, p.45-56, 1985.

STORRY, J.E.; HALL, A.J.; JOHNSON, V.W. The effects of increasing amounts of dietary tallow on milk-fat secretion in the cow. Journal of Dairy Research, v.40, p.293, 1973.

Van NEVEL, C.J.; DEMEYER, D.I. Manipulation of ruminal fermentation. In: HOBSON, P.N. The ruminal microbial ecosystem. Essex: Elsevier, 1988 p.387-443.

VILLELA, S.D.J. Utilização do caroço de algodão na alimentação de vacas em lactação. Viçosa, MG: Universidade Federal de Viçosa, 1995. 85p. Dissertação (Mestrado em Zootecnia) - Universidade Federal de Viçosa, 1995.

WU, Z. et al. Effect of source and amount of supplemental fat on lactation and digestion in cows. Journal of Dairy Science, v.77, n.6, p.1644-1651.

YANG, C.M.J.; RUSSELL, J.B. The effect of monensin supplementation on ruminal ammonia accumulation in vivo and the numbers of amino acid-fermenting bacteria. Journal of Animal Science, v.71, p.3470-3476, 1993. 